\title{
Zn dopant effect on growth, morphology, texture and mechanical properties of $\mathrm{SnO}_{2}$ thin films
}

\author{
F. Paraguay-Delgado*, A. Hurtado-Macías, O. Solís-Canto \\ Centro de Investigación en Materiales Avanzados SC, Laboratorio Nacional de Nanotecnología \\ Chihuahua, Chih, 31136, México.
}

(Received: October 6th, 2017; Accepted: December 27th, 2017)

\begin{abstract}
When tin oxide thin film is doped with $\mathrm{Zn}$, it grows textured and improves its mechanical properties. The material was synthesized on alkali-free borosilicate glass substrates by spray pyrolysis technique. The elemental composition was determined by X-ray energy dispersive spectroscopy and X-ray photoelectron spectroscopy. The morphology and microstructure of films were examined by electron microscopy techniques, they shown different shapes of crystalline particles according to the dopant content. From X-ray diffraction patterns processed by Rietveld refinement methodology was determine lattice parameters, crystallite sizes and micro strain; it showed that the textural growth of the films depend on the $\mathrm{Zn}$ dopant quantity content. The mechanical property was studied as a function of dopants amount, it enhancement due to the texture direction growth. For optimized $\mathrm{Zn}$ doped quantity in the film, local measurement of hardness and elastic modulus increased from 12 to $23 \mathrm{GPa}$ and from 137 to $195 \mathrm{GPa}$, respectively. According to the $\mathrm{Zn}$ content, the materials show good correlation between elastic module values and (200) texture growth direction parallel to the substrate.
\end{abstract}

\section{Introduction}

Zinc doped tin oxide thin film semiconductor improves its mechanical properties, suitable for different technology applications. Doped tin oxide is used for solar cells [1], gas sensor [2], photo catalysis [3], pollutants detection [4], anode for ion lithium batteries [5] as quantum dots [6,7], ferromagnetic [8] and photoconductive devices. Nowadays, $\mathrm{Zn}$ doped $\mathrm{SnO}_{2}$ show promising applications for high temperature semiconductor [9] and optoelectronics devices [10], both properties are being improved by tuning the amount and type of dopants. In solar energy research, $\mathrm{Zn}$ doped $\mathrm{SnO}_{2}$ nanoparticles (NPs) are being used as photo anode material to induce negative shift in the flat-band potential to increase the isoelectric point in dye-sensitized solar cell [11]. Doped tin oxide as thin films show high optical transparency and good electrical conductivity for optoelectronic applications [12], then it is significant to determine its growing, structure, elastic deformation and resistance to permanent deformation. When the mechanical properties (MPs) are known, it can be used effectively in electrochemical, photoconductive devices, transparent conductive oxide electrodes for thin film solar cells and other devices. The mechanical indentation has been the most commonly used technique to measure the MPs of materials due to the easy data acquisition. This traditional indentation test consist in acquiring the optical image of the indent and taking the measurements from it. This method, clearly imposes a lower limit on the deep scale of the indentation test. During the past two decades, the scope of indentation testing has been extended to the nanometer range. This has been achieved mainly through the development of adequate instrumentation with the capacity to measure simultaneously the load and displacement during the indentation process $[13,14]$. In recent years, the MPs (elastic modulus, hardness, stiffness, and resistance to permanent deformation) study of materials on the nanoscale has expected attention due to these properties, which are dependent on the size $[15,16]$. These studies have motivated the development of nanocomposites and their technology application as thin films, useful for miniaturization the electronic components and for generation of new technologies [17]. On the other hand, a recently developed technique to measure MPs are the continuous stiffness measurement (CSM) method [18], it offers a significant improvement in the thin film nanoindentation testing, this technique gives good accuracy to determine the values and it was used to study our samples. Several techniques have been employed to synthesize tin oxide based coatings such as sol-gel [19], radio frequency reactive magnetron sputtering [20], chemical vapor deposition [21] and its variants as spray pyrolysis (SP) $[22,23]$. Among these techniques, SP has proved to be easy, reproducible and technically a good way for adding dopant elements, it has high grown rate and cheap method to mass production of uniform large-scale area coatings, which is desirable for industry and solar cell production. As regards to the dopant presence, by SP is possible to obtain doped and textured thin films growth, then evaluate mechanical properties of the material.

In this report, the aim is to investigate the influence of the $\mathrm{Zn}$ dopant concentration on the growing characteristics; surface morphology and microstructure of $\mathrm{SnO}_{2}$ thin films, with exhaustive structural characterization using Rietveld refinement method to process the XRD patterns and correlate with mechanical properties. The studied samples were obtained by SP technique due to the advantages mentioned above.

\section{Experimental details}

Highly textured $\mathrm{Zn}$ doped $\mathrm{SnO}_{2}$ thin films were synthesized by SP technique; the methodology has been fully described before [24,25]. In summary, we have used a SP system including a mobile platform that provides an 
oscillatory movement to the spray nozzle. The starting solution was a dilution of tin tetrachloride $(0.05 \mathrm{M})$ in methanol. Zinc acetate was used as a dopant source and the atomic ratio between $\mathrm{Zn}$ and $\mathrm{Sn}$ was varied from 1 up to 33 at\%. Corning $7059\left(2.5 \times 7.5 \mathrm{~cm}^{2}\right)$ glass slides were used as substrate, the synthesis temperature was fixed at $773 \pm 5 \mathrm{~K}$. Micro-filtered air was used as a carrier gas; their pressure and flux were kept at $310 \mathrm{kPa}$ and $4 \mathrm{~L} / \mathrm{min}$, respectively. The deposition process was intermittent, one sweep movement was spraying dissolution and two without spraying; the effective deposition time was around 4 min in order to get the same thickness among the samples. Table 1 shows the main synthesis parameters values and characteristics for the samples under study.

The thickness of the films were determined from near normal reflectance spectrum, acquired by Filmetrix F-20UV reflectance spectrophotometer. Surface morphology of the films were analysed by Field Emission Scanning Electron Microscopy (FESEM) model JEOL JSM-7401F and the microstructure was studied by analytical Transmission Electron Microscopy (TEM) using Philips CM-200 and JEOL JEM-2200FS instruments, the images were acquired in TEM and STEM modes. For TEM study, samples were made by two methods: first one the sample was scratch and immersed in $5 \%$ content of flourhydric acid in water, then it was floating directly the film from the glass slide by tension superficial in water and mounted it on a copper grid, and the second one was made using Focus Ion Beam (FIB) milling to study thin films cross section. The FIB equipment to make the sample was Jeol JEM-9320FIB with Ga ion source. The chemical composition of the films were found by X-ray photoelectron spectroscopy (XPS), Escalab 250Xi spectrometer and by X-ray energy dispersive spectroscopy (EDS), attached to both SEM and TEM microscopes. Raman spectra were acquired using a LabRam HR Vis-633 Horiba Micro Raman spectrometer with He-Ne Laser emitting at $632.8 \mathrm{~nm}$. The spectra was acquired from 3 zones and the resultant intensity values were average, the exposure time for each one was $5 \mathrm{~min}$, the microscope objective was $100 \times$ and grating was 1800 groves $/ \mathrm{mm}$. The atomic force images were acquired by Veeco SPM MultiMode IV working in tapping mode. Nano MPs such as hardness $(\mathrm{H})$ and elastic modulus (E) of the samples were measured by nano-indentation technique using continuous stiffness measurement (CSM) method, by Nano Indenter G200 coupled with a DCM II head. The instrument was calibrated using a standard fused silica sample to find area function constants, being $\mathrm{C}_{0}=$ 24.05, $\mathrm{C}_{1}=-186.33, \mathrm{C}_{2}=6422.20, \mathrm{C}_{3}=-26452.23$ and $\mathrm{C}_{5}=$ 18012.30. The calibration of the equipment is very important due to the damage or worn of the Berkovich

Table 1. Films synthesis parameters and characteristics. Rietvel refinement results.

\begin{tabular}{|c|c|c|c|c|c|c|c|c|c|c|c|c|c|}
\hline \multirow[b]{2}{*}{ 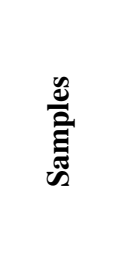 } & \multirow{2}{*}{ 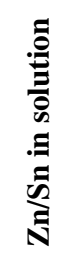 } & \multirow[b]{2}{*}{ 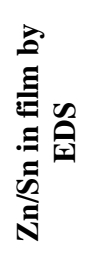 } & \multirow{2}{*}{ 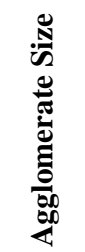 } & \multirow[b]{2}{*}{ 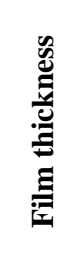 } & \multirow[b]{2}{*}{ 茎 } & \multicolumn{8}{|c|}{ Results from XRD with Rietvel Refinement } \\
\hline & & & & & & 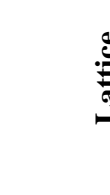 & 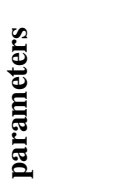 & 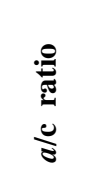 & 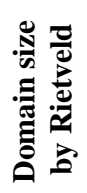 & 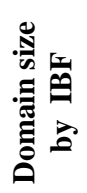 & 弟 & $\begin{array}{l}\vec{E} \\
\frac{000}{d} \\
\overrightarrow{3}\end{array}$ & 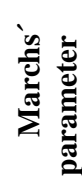 \\
\hline & \multicolumn{2}{|c|}{$(\mathbf{a t} \%)$} & $(\mathbf{n m})$ & $(\mathbf{n m})$ & $(\mathrm{nm} / \mathrm{s})$ & $a(\mathbf{n m})$ & $\mathbf{c}(\mathbf{n m})$ & & \multicolumn{2}{|c|}{$(\mathbf{n m})$} & $(\boldsymbol{h k l})$ & $(\%)$ & G1 \\
\hline JCPDS & & & & & & 0.4738 & 0.3187 & 1.486 & & & & & \\
\hline \multirow{3}{*}{ ZN01 } & \multirow{3}{*}{0.0} & \multirow{3}{*}{0} & \multirow{3}{*}{323} & \multirow{3}{*}{325} & \multirow{3}{*}{85} & \multirow{3}{*}{0.4729} & \multirow{3}{*}{0.3177} & \multirow{3}{*}{1.489} & \multirow{3}{*}{32} & \multirow{3}{*}{35} & $(110)$ & 33 & 0.425 \\
\hline & & & & & & & & & & & (100) & 33 & 0.426 \\
\hline & & & & & & & & & & & $(211)$ & 33 & 0.273 \\
\hline \multirow{2}{*}{ ZN02 } & \multirow{2}{*}{1.0} & \multirow{2}{*}{ ND } & \multirow{2}{*}{272} & \multirow{2}{*}{467} & \multirow{2}{*}{121} & \multirow{2}{*}{0.4727} & \multirow{2}{*}{0.3177} & \multirow{2}{*}{1.488} & \multirow{2}{*}{25} & \multirow{2}{*}{33} & (200) & 93 & 0.350 \\
\hline & & & & & & & & & & & $(101)$ & 7 & 0.334 \\
\hline \multirow{2}{*}{ ZN03 } & & & & & & & & & & & (200) & 55 & 0.288 \\
\hline & 2.9 & ND & 191 & 439 & 114 & $0.4 / 40$ & 0.3181 & 1.492 & 10 & 23 & (101) & 45 & 0.357 \\
\hline & & & & & & & & & & & (200) & 51 & 0.319 \\
\hline ZN04 & 4.8 & ND & 204 & 390 & 101 & $0.4 / 44$ & 0.3175 & 1.494 & 16 & 20 & $(101)$ & 49 & 0.394 \\
\hline 7N05 & 65 & ND & 244 & 310 & 85 & 04733 & 03172 & 1492 & 16 & 21 & (200) & 59 & 0.328 \\
\hline Z1NUS & 0.5 & ND & 244 & 310 & 85 & $0.4 / 33$ & $0.31 / 2$ & 1.492 & 10 & 21 & $(101)$ & 41 & 0.381 \\
\hline ZN06 & 91 & $\mathrm{ND}$ & 208 & 337 & 88 & 04743 & 03178 & 1492 & 16 & 21 & (200) & 44 & 0.328 \\
\hline 21 & 9.1 & IVD & 200 & 351 & 00 & 0.4145 & 0.5170 & 1.492 & 10 & 21 & $(101)$ & 56 & 0.398 \\
\hline ZN07 & 23.8 & 0.5 & 156 & 274 & 71 & 04734 & 03167 & 1495 & 12 & & (200) & 3 & 0.273 \\
\hline & & & & & 11 & $0.4 / 34$ & $0.310 /$ & 1.493 & 12 & 10 & $(101)$ & 97 & 0.492 \\
\hline & 333 & & & 244 & & & & & & & (200) & 8 & 0.316 \\
\hline ZNO8 & 33.3 & 1 & 154 & 244 & 03 & $0.4 / 03$ & 0.3160 & 1.485 & 13 & 19 & (101) & 92 & 0.458 \\
\hline
\end{tabular}

ND: Not Detected by EDS; JCPDS for reference values. Dopant concentration at\% Zn/Sn in solution and in film; Agglomerate size; Film thickness and Growth rate. Rietvel refinement results: Lattice parameters a, c, a/c Ratio; Domain size (by refinement and from intensity broadening fit (IBF)); Texture directions used in Rietveld analysis with their respective weight percentage and first Marchs' parameters values. 
diamond tip, which can affect the area in which it functions the contact penetration depth $h_{c}, A\left(h_{c}\right)$ [26]. The area function has the following polynomial equation:

$$
A\left(h_{c}\right) \approx C_{0} h_{c}^{2}+C_{1} h_{c}+C_{2} h_{c}^{1 / 2}+C_{3} h_{c}^{1 / 4}+C_{4} h_{c}^{1 / 8}+C_{5} h_{c}^{1 / 16}
$$

The area function for a perfect Berkovich indenter is given by $A=24.56 h_{c}^{2}$. Indenters used in practical nanoindentation testing are not ideally sharp. Therefore, the tip geometry calibration or area function calibration is needed.

We use Berkovich diamond indenter with a tip radius of $20 \pm 5 \mathrm{~nm}$, depth limit of $140 \mathrm{~nm}$ and strain rate of $0.05 \mathrm{~s}^{-1}$. The harmonic displacement and frequency was $1 \mathrm{~nm}$ and $75 \mathrm{~Hz}$ passion's coefficient of $v=0.22$, respectively. Residual indentation of samples was recorded by AFM Nano Vision system attached to the instrument.

Crystal structure of the materials was evaluated by X-ray diffraction (XRD) in Bragg-Brentano geometry using a Philips X-Pert diffractometer; the patterns were acquired with $40 \mathrm{kV}$ and $30 \mathrm{~mA}$, using $\mathrm{Cu} \mathrm{K} \alpha(\lambda=0.15418 \mathrm{~nm})$ radiation and the scanning angle $2 \theta$ varied between $20^{\circ}$ and $80^{\circ}$, with $0.015^{\circ}$ step. Lattice parameters, crystallite sizes, micro strain and preferential growth orientation were obtained through the Rietveld refinement method [27]. The refinement of XRD patterns were performed through the free software Fullprof, the criteria and sequence of refinement was achieved following the method proposed by Fuentes [28]. The starting structural model for $\mathrm{SnO}_{2}$ refinement was built with crystallographic data reported in Inorganic Crystal Structure Database 2004.

\section{Results and discussion}

\section{Composition and growth rate}

Zinc atomic percentage content in the starting solution and films are listed in Table 1. The dopant concentration in the synthesized materials do not correspond to the same amount in the precursor dilution. Although the dopant do not totally enter into the film but it has strong influence on the growth characteristics and its MPs. The $\mathrm{Zn}$ atoms amount in the films were lower than the detection limit by EDS, for the samples ZN02 up to ZN06 (until $9.1 \mathrm{Zn} / \mathrm{Sn}$ at\% in dilution). In the case of the films obtained with higher $\mathrm{Zn}$ content in dilution, it was possible to detect by EDS and it was reported in the Table 1. In the rest of this work, the dopant percentage is referred to the start dilution amount, if not stated otherwise. The thickness growth rate was also influenced by the dopant concentration in the start dilution. First, it was perceived an important increase on the growth rate (44\%) for the sample with 1 at $\%$ of $\mathrm{Zn} / \mathrm{Sn}$ in relation to the undoped sample. Then the growth rate decreased systematically as the $\mathrm{Zn}$ content increased in the precursor dilution (see Table 1). The $\mathrm{Zn}$ quantity content and grown rate changes on the films could be due to changes in the precursor dilution properties, since the $\mathrm{pH}$ changes slightly with the $\mathrm{Zn}$ amount content, this type of behavior was also reported by Bilgin et al. [29].

With the purpose to find $\mathrm{Zn}$ as a dopant in the $\mathrm{SnO}_{2}$ films, a couple of samples have been analyzed by XPS technique. Figure 1 shows the core level high resolution XPS spectra of

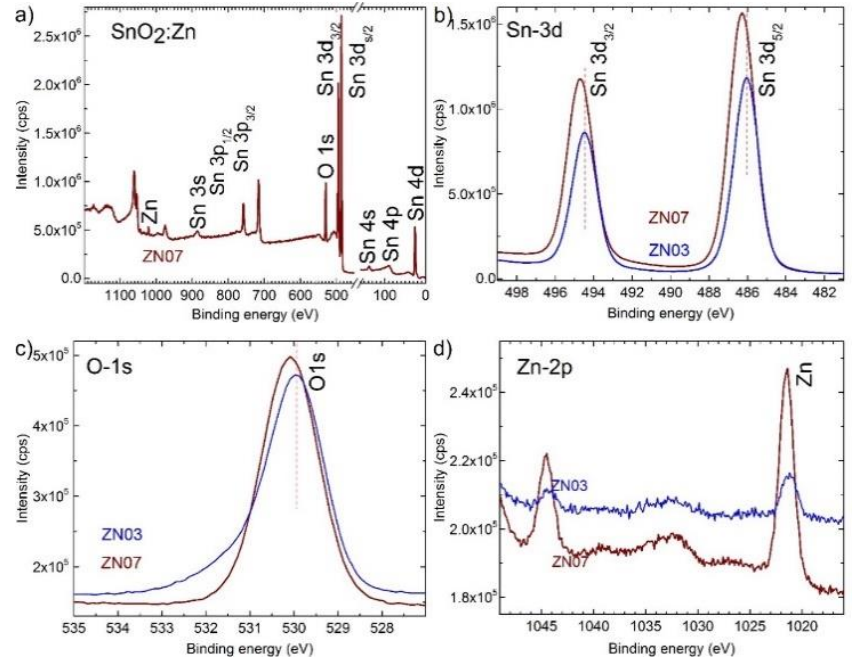

Figure 1. XPS analysis of $\mathrm{Zn}$ doped $\mathrm{SnO}_{2}$ thin films for 2.9 and 23.8 at $\%$ $\mathrm{Zn} / \mathrm{Sn}$ samples; (a) General spectra, (b) $\mathrm{Sn} 3 \mathrm{~d}$, (c) O $1 \mathrm{~S}$ and (d) Zn 2p peaks.

Sn-3d, O-1s and Zn-2p for 2.9 and 23.8 at $\%$ of Zn/Sn (ZN03 and ZN07) samples. Figure 1a shows the binding energies of the sample, confirming the presence of tin, oxygen and dopant $\mathrm{Zn}$. Figure $1 \mathrm{~b}$ shows in detail, the binding energy of Sn $3 \mathrm{~d} 5 / 2$ and $3 \mathrm{~d} 3 / 2$ peaks with spin orbit separation of 8.42 $\mathrm{eV}$, which are localized at 486.06 and $494.48 \mathrm{eV}$ for 2.9 at\% of $\mathrm{Zn} / \mathrm{Sn}$ (sample ZN03); this binding energy of Sn 3d corresponds to $\mathrm{Sn}+4$ ion (oxidative state). Although, the values reported by NIST XPS database for $3 d_{5 / 2}$ and $3 d_{3 / 2}$ are 486.6 and $494.50 \mathrm{eV}$, respectively; our measurement values are close. Comparing the binding energy values for $\mathrm{Sn} 3 \mathrm{~d}_{5 / 2}$ and $3 \mathrm{~d}_{3 / 2}$ intensities, for 2.9 and 23.8 at $\%$ of $\mathrm{Zn} / \mathrm{Sn}$ content samples, there is a $0.24 \mathrm{eV}$ shift toward upper energy for high $\mathrm{Zn}$ content sample (ZN07). This binding energy variation of Sn-3d core level with $\mathrm{Zn}$ doping can be qualitatively attributed to the formation of $\mathrm{Zn}-\mathrm{O}-\mathrm{Sn}$ bond. The electronegativity of $\mathrm{Zn}(1.65)$ is less than of $\mathrm{Sn}$ (1.96) and the electrons density around $\mathrm{Zn}$ atom in $\mathrm{Zn}-\mathrm{O}-\mathrm{Sn}$ bond is lower than that in Sn-O-Sn bond, which causes the upward shift of the Sn-3d core level energy. Figure 1c shows the O$1 \mathrm{~s}$ transition peak and also an upward shift from 529.93 to $530.07 \mathrm{eV}$ for the sample with high $\mathrm{Zn}$ content, it is another consequence of the $\mathrm{Zn}-\mathrm{O}-\mathrm{Sn}$ bond formation, The energy values is according to reported literature and do not belongs to $\mathrm{ZnO}$, it belongs to $\mathrm{O} \mathrm{K}$ level binding. Figure $1 \mathrm{~d}$ shows the binding energy of the $\mathrm{Zn} 2 \mathrm{p}_{3 / 2}$ and $\mathrm{Zn} 2 \mathrm{p}_{1 / 2}$ transition intensities, which confirms the presence of $\mathrm{Zn}$ dopant in the $\mathrm{SnO}_{2}$ films, the relative intensity change shows the $\mathrm{Zn}$ amount contents qualitatively. Due to these results it could be concluded that the $\mathrm{Zn}$ dopant was incorporated by substitution to $\mathrm{Sn}$ atoms into the $\mathrm{SnO}_{2}$ lattice to form $\mathrm{Zn}-\mathrm{O}$ Sn bonds.

\section{Structure and texture results}

Figure 2a shows the X-ray diffraction patterns, the signal for undoped sample has different intensities and for doped films they changes systematically. It can be noticed a systematic change of patterns intensities, starting strong intensity from (200) toward (101) direction for low and high 

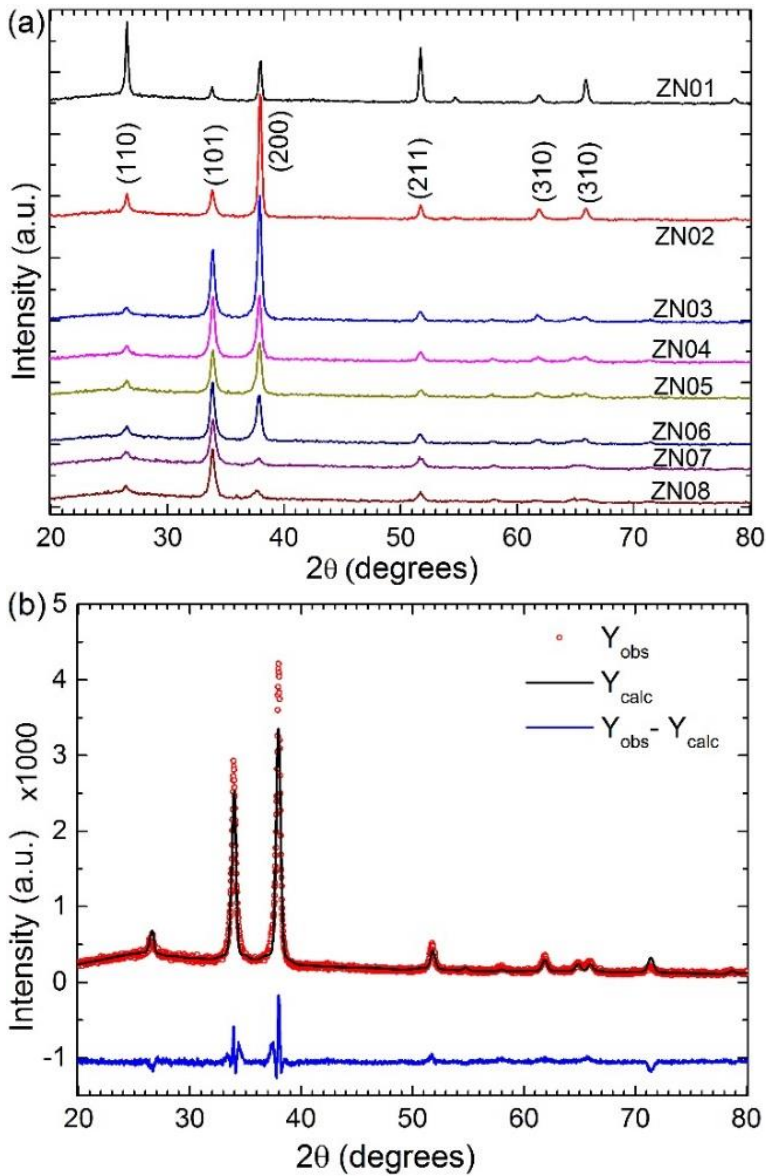

Figure 2. X-Ray diffraction patterns for (a) $\mathrm{Zn}$-doped $\mathrm{SnO}_{2}$ thin films and (b) typical Rietvel refinement spectra for 2.9 at $\%$ of $\mathrm{Zn} / \mathrm{Sn}$.

Zn dopant amount content samples, respectively. All patterns show polycrystalline structure and they index with JCPDS card number 41-1445, it was not detected other phases corresponding to zinc oxide or to new tin-zinc compounds. Taking the pattern intensities for undoped $\mathrm{SnO}_{2}$ as reference, the $\mathrm{Zn}$ doped $\mathrm{SnO}_{2}$ films present changes according to the $\mathrm{Zn}$ dopant content increase. These results indicate that doped films grew with systematic preferential orientation, according to the $\mathrm{Zn}$ content. In addition, the pattern intensities decreases and its wide increases; then the crystallinity of films decreases systematically as the $\mathrm{Zn}$ concentration increases. Table 1 shows the summary of the principal parameters obtained from Rietveld refinement for all films analyzed in this work. Figure $2 b$ shows a typical example of the Rietveld refinement methodology results for each XRD patterns, this figure in particular represents the refinement for 2.9 at\% $\mathrm{Zn} / \mathrm{Sn}$ (sample ZN03).

The lattice parameters of $\mathrm{SnO}_{2}$ changes slightly as a function of $\mathrm{Zn}$ amount content, these values have been obtained from Rietveld refinement (Table 1). Figure 3 shows the lattice parameters difference in comparison with values reported in JCPDS card 41-1445. It can be noticed that the lattice parameter "a" and "c" for films with Zn dopants start increase in order of two thousandth for films contents up to 2.9 at $\% \mathrm{Zn} / \mathrm{Sn}$ and then for higher $\mathrm{Zn}$ dopant contents decrease systematically; this change could be due to the unit

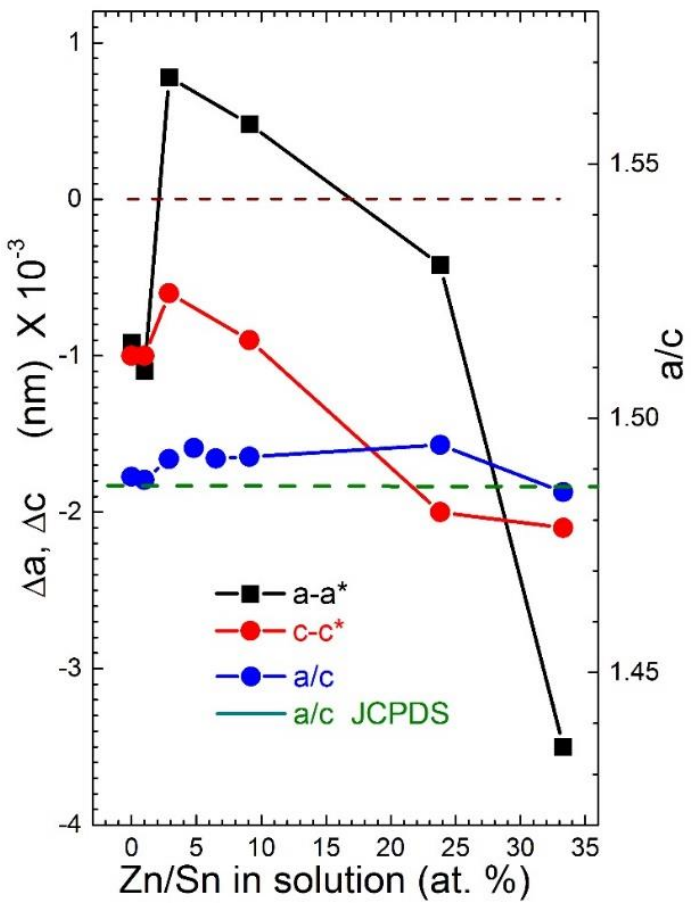

Figure 3. Lattice parameters difference (a-a* and c-c*) as a function of $\mathrm{Zn}$ contents. $\mathrm{a}^{*}=0.47382 \mathrm{~nm}$ and $\mathrm{c}^{*}=0.31871 \mathrm{~nm}$ belongs to JCPDS $41-1445$. It is include the $\mathrm{a} / \mathrm{c}$ ratio variation.

cell growth orientation relative to the substrate, due to the $\mathrm{Zn}$ atom binding ( $\mathrm{Zn}-\mathrm{O}-\mathrm{Sn})$. Therefore, for all films with the exception of ZN08 (33.3 at\%) sample, the ratio a/c was less than that of the reference diffraction file; it showed the trend to increase with the $\mathrm{Zn}$ content (see Table 1 and Figure 3).

Moreover, we have also obtained the domain size, as a function of $\mathrm{Zn}$ amount contents. The average size decreases generally starting from $32 \mathrm{~nm}$ for undoped up to $12 \mathrm{~nm}$ for 23.8 at $\% \mathrm{Zn} / \mathrm{Sn}$ doped material. These values were determined from the XRD pattern intensity broadening fit (IBF) using the Scherrer equation [23], it was calculated for each most strong diffraction intensities, respectively; the tendency of these values is consistent with that domain size obtained by Rietveld method, as the Table 1 shows. Another remarkable result obtained was the preferred growth orientation of the films, similar to indium doped zinc oxide thin film [22] reported previously. In brief, the Rietveld method calculate diffraction intensities as a function of Bragg reflection angle, Lorentz polarization factors, structure factor, intensity profile function, absorption factor and preferred orientation function or denominate pole density distribution Pg. The Fullprof program could consider as two or three phases of the same compound (same lattice parameters with different texture), using this option was refined the XRD (see Table 1 texture directions and their weight percentages). The Pg was evaluate using MarchDollase function (see Table 1 Marchs' parameter values), the preferred grown of each studied film was determined evaluating this function, for every texture, then each one was weighted with their percentage; more details in [22]. This semi-quantitative evaluation of the inverse pole figure (IPF), in the normal direction to the substrate surface, was achieved 


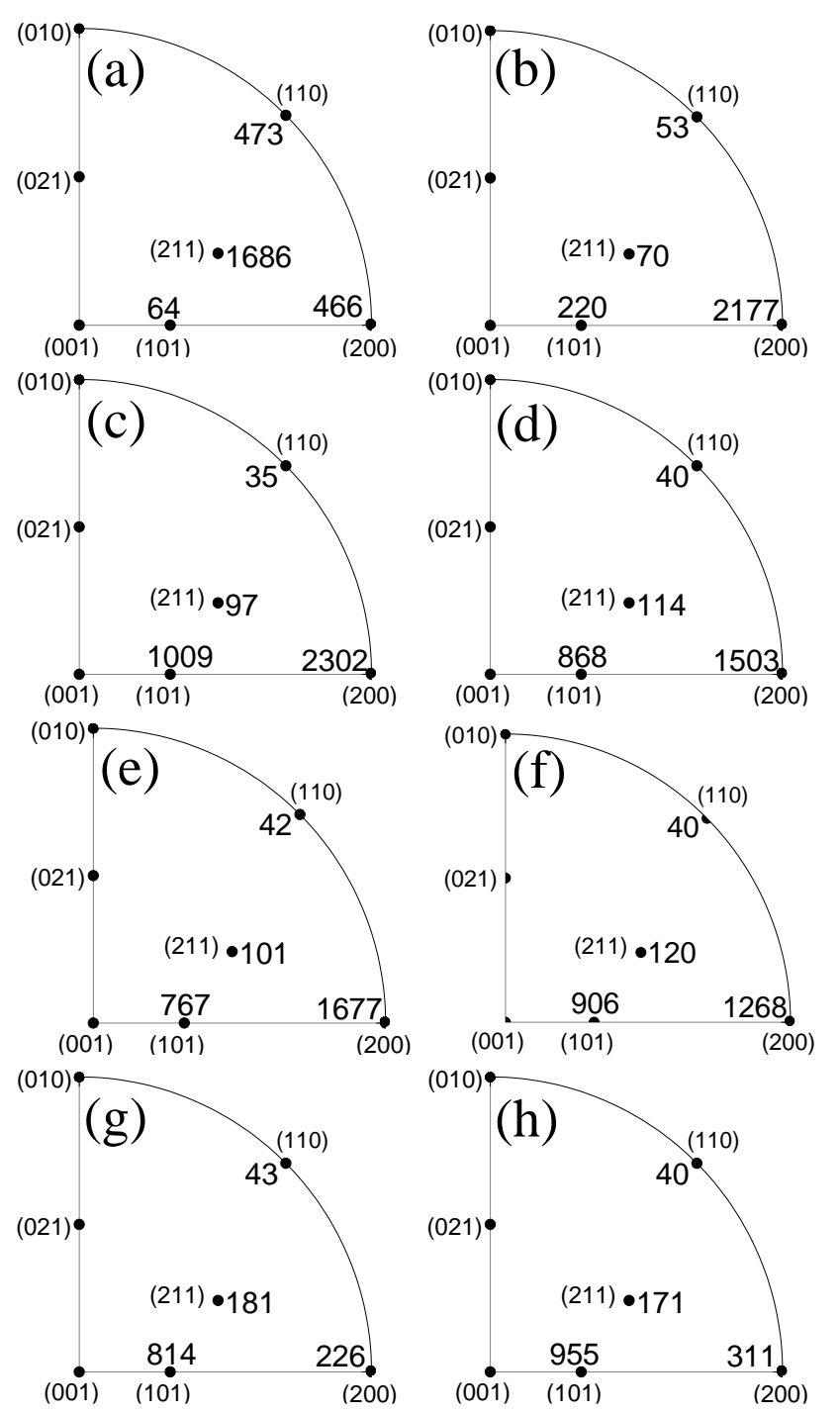

Figure 4. Inverse pole figure for $\mathrm{Zn}$ doped $\mathrm{SnO}_{2}$ thin films: (a) undoped, (b) 1 , (c) 2.9 , (d) 4.8 , (e) 6.5 , (f) 9.1 , (g) 23.8 and (h) 33.3 at $\% \mathrm{Zn} / \mathrm{Sn}$.

for all observed intensities in the XRD patterns. The IPF determination for (200) intensity, initially increases abruptly for samples up to $6.5 \mathrm{at} \% \mathrm{Zn} / \mathrm{Sn}$ content, then it changed to (101) intensity from samples with 9.1 to 33.3 at $\% \mathrm{Zn} / \mathrm{Sn}$ contents systematically. Figure 4 shows the IPF calculated values for studied samples, the (200) and (101) d-space have a marked tendency to grown parallel to the substrate surface. Therefore, $\mathrm{Zn}$ dopant concentration generate changes in the $\mathrm{SnO}_{2}$ films growth orientation, in the (200) or (101) direction. These findings indicate that for higher $\mathrm{Zn}$ dopant presence in the started solution modifies the growth direction of the resulting $\mathrm{SnO}_{2}$ material by decelerating slightly the thickness growth rate, decreasing the particles agglomeration and domain size. The $\mathrm{SnO}_{2}$ film thickness growth rate in (200) direction is faster than (101), this is due to the properties changes of the start solution due to the $\mathrm{Zn}$ acetate salt quantity contents for doping purpose; the other reason, is the $\mathrm{Sn}$ and $\mathrm{O}$ atoms rate addition on the (200) and (101) $\mathrm{SnO}_{2}$ surface layer, it could be different due the atomistic affinity. The $\mathrm{SnO}_{2}$ mass densification is in the (200) direction and it is the preferred growth than others intensities by SP technique, being the optimum growing rate at 1 at $\%$ $\mathrm{Zn} / \mathrm{Sn}$ amount content.

A complementary study about the structure was made by Raman spectroscopy. The spectra for all studied films have similar behavior such as shown in Figure 5. They show the presence of three characteristic vibration bands located at 479, 629 and $772 \mathrm{~cm}^{-1}$ which belongs to $E_{g}, A_{1 g}$ and $B_{2 g}$ vibrational modes for $\mathrm{SnO}_{2}$ rutile structure, respectively [30]. Our values is slightly shifted toward the left around 3 $\mathrm{cm}-1$ respect to the reference, it is probably due to the dopant presence. It was do not notice the vibration modes of $\mathrm{ZnO}$ for any concentration. The $\mathrm{E}_{\mathrm{g}}$ and $\mathrm{B}_{2 \mathrm{~g}}$ bands represent the vibration modes with displacement in the direction of the $\mathrm{c}$ axis, $A_{1 g}$ show the vibrations with displacements perpendicular to the $\mathrm{c}$-axis and $\mathrm{B}_{2 \mathrm{~g}}$ represents asymmetric $\mathrm{Sn}-\mathrm{O}$ stretching of $\mathrm{SnO}_{2}$. The signals for thin films show strong and wide intensity of $\mathrm{E}_{\mathrm{g}}$ band but when the material is powder type show a strong intensity for A1g vibration mode [31]. The Eg vibration intensity decrease for high $\mathrm{Zn}$ at\% of $\mathrm{Zn} / \mathrm{Sn}$, this widening of the intensity shape is due to the nanometric domain size, due to the phonon confinement. These variations in the intensities and shape is another evidence about the presence of $\mathrm{Zn}$ as a dopant in the $\mathrm{SnO}_{2}$ films.

\section{Morphology and microstructure}

Thin films surface morphology was studied by SEM and AFM but the particle microstructure, shape and cross sectional evolution was studied by TEM. Figure 6 shows SEM images acquired with secondary electrons for different Zn percentages contents samples: (a) undoped; (b) 1; (c) 4.8 and (d) 33.3 at\% $\mathrm{Zn} / \mathrm{Sn}$. For each one, it was included inset cross section image, both images show in detail the thickness growth and crystals agglomeration. It can be noticed that the

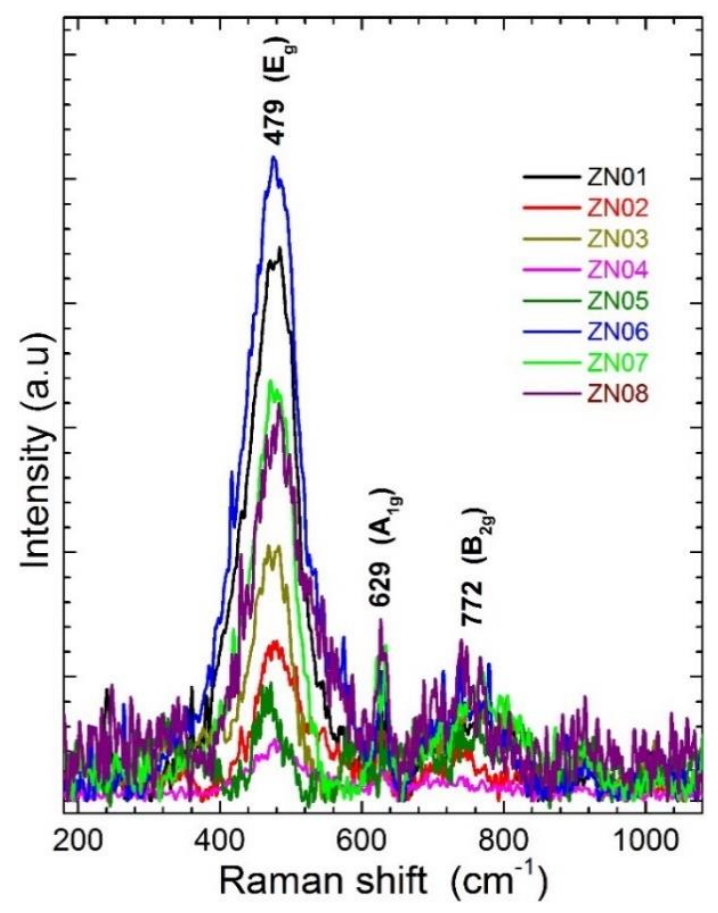

Figure 5. Raman spectra for all $\mathrm{Zn}$ doped $\mathrm{SnO}_{2}$ thin films. 


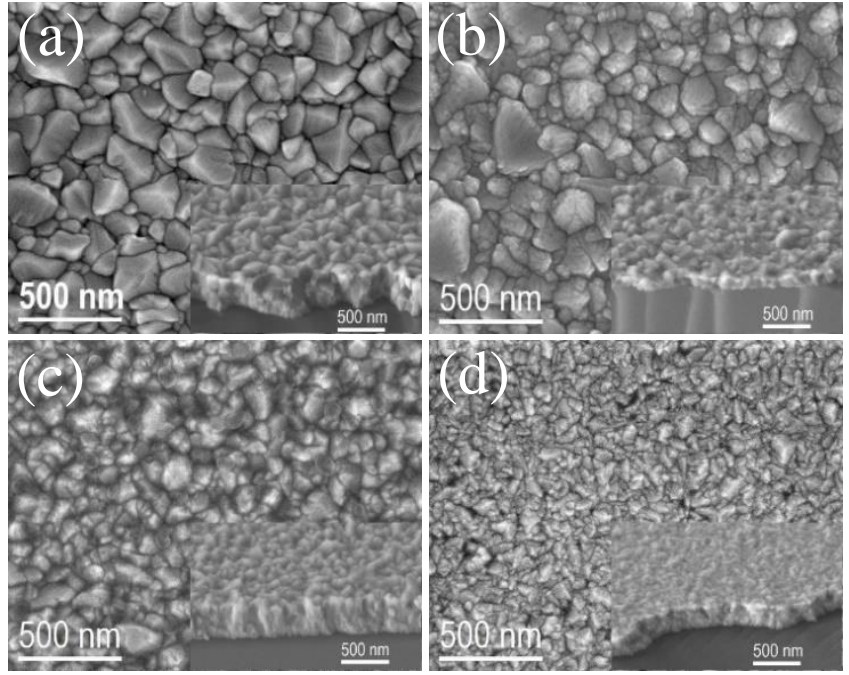

Figure 6. SEM micrographs for (a) undoped, (b) 1, (c) 4.8 and (d) 33.3 at $\%$ $\mathrm{Zn} / \mathrm{Sn}$.

film's microstructure has been influenced by $\mathrm{Zn}$ dopant content. Figure 6a shows image from undoped film, the particle agglomerate average size is around $323 \mathrm{~nm}$, this film does not present any noticeable texture, as determine by XRD pattern (Figure 2a). Figure 6b shows the image for sample with 1 at $\% \mathrm{Zn} / \mathrm{Sn}$, it can be seen a similar morphology than undoped sample but with diminished particle agglomerate average size around $272 \mathrm{~nm}$, this sample has a marked (200) preferential growth orientation, parallel to the substrate. Figure $6 \mathrm{c}$ shows the morphology of the sample with 4.8 at $\% \mathrm{Zn} / \mathrm{Sn}$, it could be see the particle agglomerates size are homogeneous, with average size approximately $204 \mathrm{~nm}$, this sample has a slightly preferential growth in the (101) direction and it starts to change from (200) growth direction. Figure 6d shows the morphology of sample with 33.3 at $\% \mathrm{Zn} / \mathrm{Sn}$, it can be noticed that the particle agglomerate size decreased to around $154 \mathrm{~nm}$ and in this case the preferential growth changed completely to (101) growth direction parallel to the substrate. It is worthwhile to mention that the apparent discrepancy between agglomerate size observed by SEM and the crystallite size determined by the Rietveld method, could be clarified by the fact that X-ray diffraction calculate the mean domain size (crystalline particle) perpendicular to the diffracting plane, i.e. in the normal direction to the substrate surface (in Bragg-Brentano geometry). Instead, in image analysis by SEM we observe the particle agglomerate size (conglomerate domain) projected on the substrate surface. SEM micrographs showed that the particle agglomerate morphology was similar for all the samples, only average size decreased as the percentage of $\mathrm{Zn}$ amount dopant increase. The Table 1 shows the agglomerate size and domain size values, both decrease when the $\mathrm{Zn}$ dopant quantity increase in $\mathrm{SnO}_{2}$ films. Thin films roughness was studied by AFM according to the dopant percentage, images are shown in Figure 7. The particle size and the flatness of the surface, decrease according to the $\mathrm{Zn}$ dopants content; the top and down distance in these images decrease systematically by the dopants amount increase in the samples. The images shown
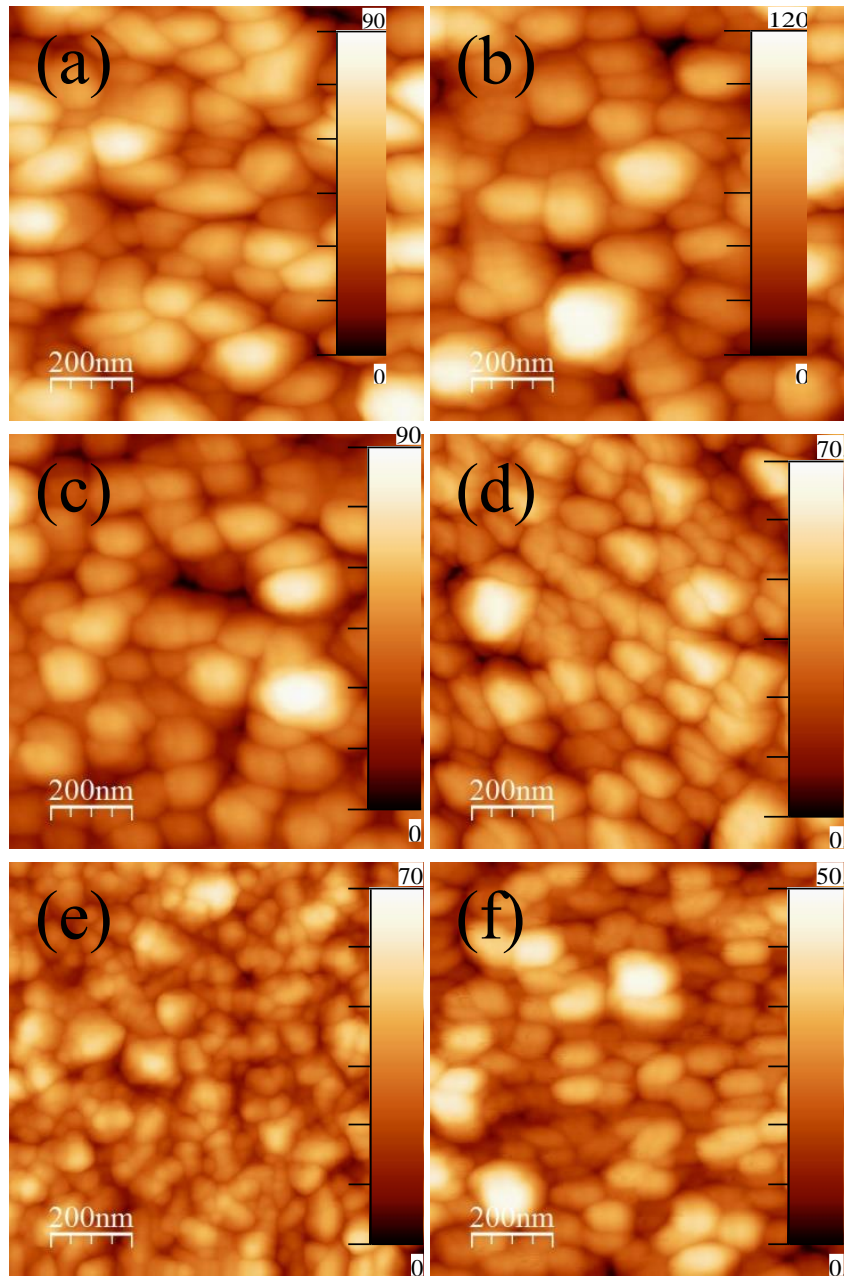

Figure 7. AFM images for (a) undoped, (b) 1, (c) 4.8, (d) 6.5, (e) 23.8 and (f) 33.3 at $\% \mathrm{Zn} / \mathrm{Sn}$ films. The $\mathrm{Z}$ direction (perpendicular to substrate) scale are in $\mathrm{nm}$ for all images.

in Figures. 7a, 7b, 7c, 7d, 7e and 7f which are from 0, 1, 4.8, $6.5,23.8$ and 33.3 at $\% \mathrm{Zn} / \mathrm{Sn}$ dopants contents, respectively. The surface roughness values determined by root mean square (RMS) methodology were included in Table 2, these values decrease with the $\mathrm{Zn}$ dopant presence, systematically. The roughness for films with higher $\mathrm{Zn}$ dopant percentage content is less than for undoped film, this type of coatings are adequate for technology applications such as solar cell buffer layer, transparent conductor and others.

The domain shapes and crystallinity were studied by TEM techniques, Figure 8 shows the micrographs and their corresponding Selected Area Electron Diffraction (SAED) patterns are include. Figure 8a shows bright field TEM image for undoped $\mathrm{SnO}_{2}$ film, without texture and its domain morphology exhibit different particle shapes, such as: globular (R), elongated (E), twinned (T) and quadrilateral (Q), each type were labeled in the micrograph. Figure $8 \mathrm{~b}$ shows dark field and bright field (inset) TEM micrographs for film with 1 at $\%$ of $\mathrm{Zn} / \mathrm{Sn}$, this film is textured in the (200) direction; in this case most of crystallites have globular shape. Figures 8c and 8d show bright field and dark field micrographs TEM for sample with 4.8 at $\% \mathrm{Zn} / \mathrm{Sn}$, respectively. In this case most of the domain crystallites are 
elongated, this sample has texture in the (200) and (101) direction, these elongated particles growth in the (101) direction such as it can be seen in the atomic resolution image (Figure 9c)

Figure 8e shows bright field TEM micrograph of the film with 23.8 at $\% \mathrm{Zn} / \mathrm{Sn}$, in this image can be noticed the presence of two different types of domain particles: globular and short-extended, the texture of this sample is almost (101). Finally, Figure $8 \mathrm{f}$ displays bright field TEM micrograph of sample with 33.3 at\% $\mathrm{Zn} / \mathrm{Sn}$, it can be appreciated that most of the domain particles have globular
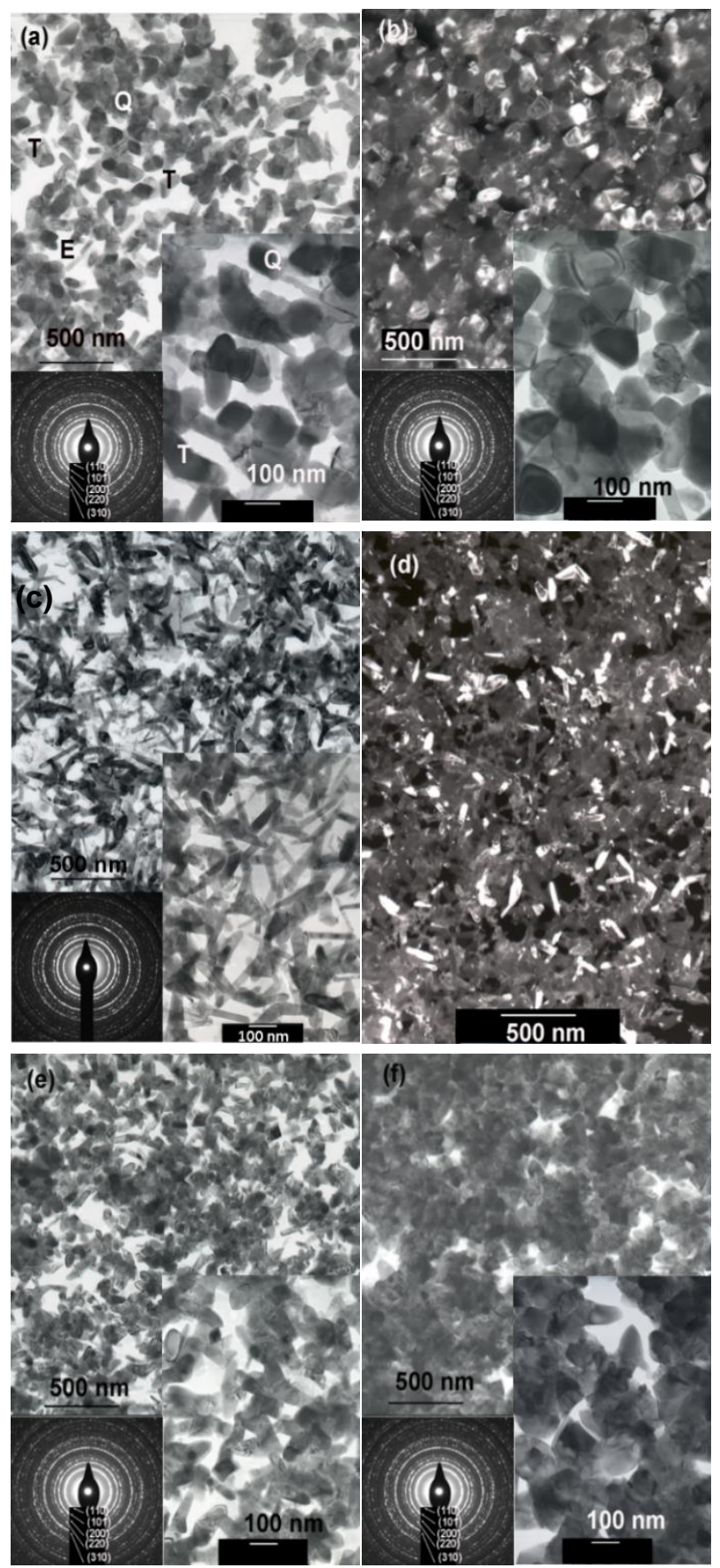

Figure 8. TEM micrographs at bright and dark field for (a) undoped, (b) 1 dark field, (c) 4.8 bright field, (d) 4.8 dark field, (e) 23.8 and (f) 33.3 at\% $\mathrm{Zn} / \mathrm{Sn}$. inset images at higher magnification and SAED patterns.
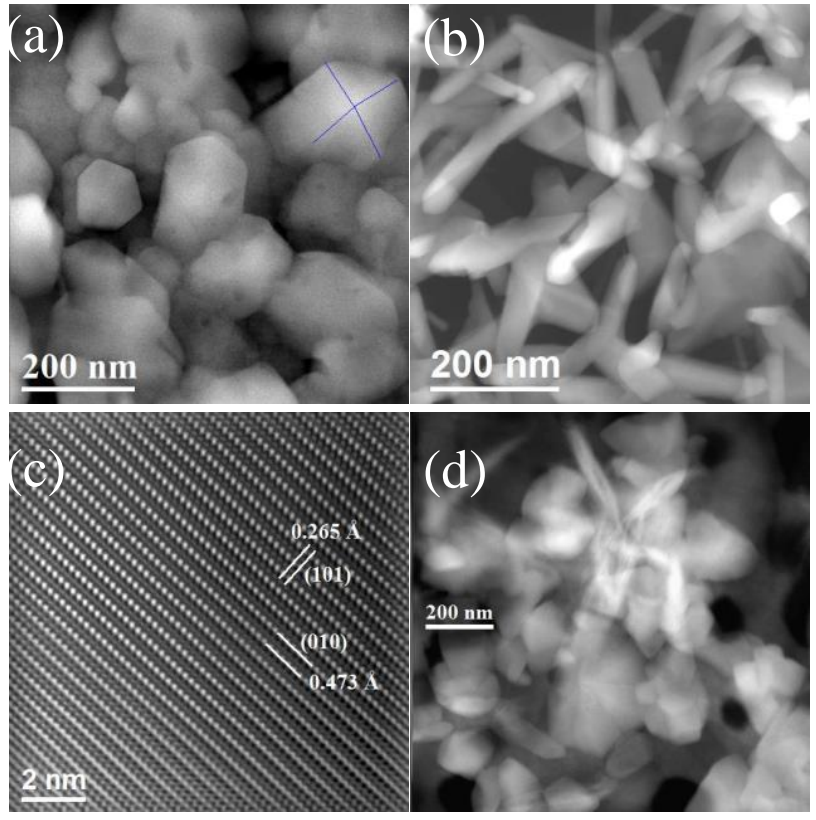

Figure 9. STEM, HAADF images for (a) undoped, (b) 4.8, (c) 4.8 HREM and (d) 23.8 at $\% \mathrm{Zn} / \mathrm{Sn}$.

or quadrilateral shape, the texture of this sample is (101) direction completely. There is no direct correlation between the shape of particles and texture growth direction of the samples according to TEM and XRD results. It is interesting to observe changes in the films' microstructure, all of them showed well-defined domain particle, each one had a dominant shape of particles and these changes are due to the $\mathrm{Zn}$ dopant quantity content. The selected area electron diffraction (SAED) are include inset of these images, all of them index well with $\mathrm{SnO}_{2}$.

The shape of the domains could be visualized better by STEM technique. Figure 9 shows STEM images acquired with HAADF detector ( $Z$ contrast), these images show apparently 3D shape of the particles. The micrograph in the Figure $9 \mathrm{a}$ is for undoped sample, it shows clearly the quadrilateral shape particles, which are squared base pyramids, this particle morphology has been visualized due to the HAADF detector, and it generates clear thickness contrast. The images in Figures $9 \mathrm{~b}$ and $9 \mathrm{c}$ are for $4.8 \mathrm{at} \%$ $\mathrm{Zn} / \mathrm{Sn}$ sample, it can be remarked that these elongated particles are not flat, they have thickness with different wide values and the end of them have a tip without well-defined shape. This changes in morphology let us understand the influence of $\mathrm{Zn}$ as dopant in the material. The micrograph $9 \mathrm{c}$ shows the atomic resolution image with $\mathrm{Z}$ contrast in a STEM mode, this image present $0.473 \mathrm{~nm}$ and $0.265 \mathrm{~nm} \mathrm{~d}$ spaces values which belongs to (010) and (101) directions, respectively. The last image (Figure 9d), shows the domain particles for 23.8 at $\% \mathrm{Zn} / \mathrm{Sn}$ sample, it shows two types of particles, globular and elongated, these particles do not show a clear shape.

Thin film d-spaces parallel to the substrate was visualized by images acquired with STEM technique. Figure 10 shows the cross section images for samples with 1 and 23.8 at $\%$ $\mathrm{Zn} / \mathrm{Sn}$, which are textured along (200) and (101) direction, respectively. The samples were made by FIB, for this reason 


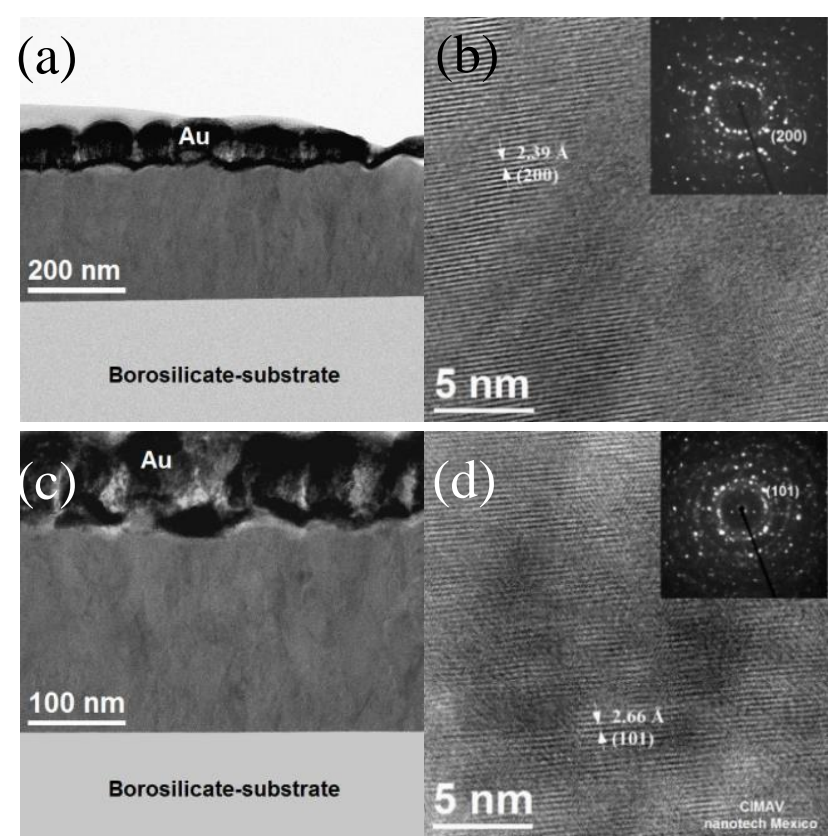

Figure 10. STEM cross-sectional view images for textured samples: (a) low mag and (b) HREM image for $1 \mathrm{at} \% \mathrm{Zn} / \mathrm{Sn}$; (c) low mag and (d) HREM for 23.8 at $\% \mathrm{Zn} / \mathrm{Sn}$; inset are the SAED patterns.

it was previously covered with $\mathrm{Au}$ layer (protection for sample preparation). Micrographs in Figures. 10a and 10b are for $1 \mathrm{at} \% \mathrm{Zn} / \mathrm{Sn}$ doped sample, which has texture in the (200) direction. The image in Figure 10b shows $2.39 \AA$ SAED pattern inset show two spots with the highest intensity that belong to (200) direction; there are other diffraction patterns spots, but they have less strong intensity. The images in Figures. 10c and $10 \mathrm{~d}$ are for 23.8 at $\% \mathrm{Zn} / \mathrm{Sn}$ doped sample, this film has (101) direction texture, the lattice distance shows (101) d-spaces parallel to the substrate; The SAED pattern is inset in the same image, it shows symmetric strong pattern intensity in the (101) direction. These thin films cross section images confirm the textured direction due to the $\mathrm{Zn}$ dopant quantity content.

According to the domain particles' shapes of the $\mathrm{Zn}$ doped $\mathrm{SnO}_{2}$ thin films, the detected texture by XRD patterns is related with a specific morphology, which were revealed by electron microscope images acquired at different modes. According to this characteristics, we studied the influence in their MPS and results are shown at the next item.

\section{Nano-mechanical properties}

The hardness $(\mathrm{H})$ and elastic module (E) were determined for each studied sample in nine positions, including for the glass substrate without thin film as reference. Figure 11a shows AFM image with nine residuals indentation positions matrix. The typical results were shown in Figure $11 \mathrm{~b}$, it is the characteristic behavior between force and displacement penetration depth. The basic nanoindentation analysis from the load-displacement curve (F-h) was established based on the elastic contact theory given by Sneddon [32] and Doerner et al [33] considering the glass substrate (corning 7059 without thin film) as a bulk. The $\mathrm{H}$ and $\mathrm{E}$ measurement values for the substrate was $11 \pm 0.5 \mathrm{GPa}$ and $92 \pm 0.5 \mathrm{GPa}$, respectively.

On the other hand, the $\mathrm{H}$ and $\mathrm{E}$ values for $\mathrm{Zn}$ doped $\mathrm{SnO}_{2}$ thin film were measured by Continuous Stiffness Measurement (CSM) methodology [34]. This is accomplished by superimposing a small oscillation on the primary loading signal and then analyzing the response of the system by means of a frequency-specific amplifier; this was done to measure the MPs of the films without the influence of the substrate. The equation to determine the stiffness (S) in CSM test is the following:

$$
S=\left|\frac{1}{\frac{F_{0}}{Z_{0}} \cos \varphi-\left(K_{s}-m \omega^{2}\right)}-\frac{1}{K_{f}}\right|^{-1}
$$

In this experiment the excitation frequency $(\omega)$ value is set. Thus $\mathrm{S}$ was evaluated by measuring the displacement amplitude $\left(Z_{0}\right)$, phase angle $(\varphi)$ and the excitation amplitude $\left(\mathrm{F}_{0}\right)$. Other parameters such as load-frame stiffness $\mathrm{K}_{\mathrm{f}}$, the stiffness of the support springs $\mathrm{K}_{\mathrm{s}}$ and mass $\mathrm{m}$ are known previously for a specific measurement instrument. With a CSM method the $\mathrm{H}$ and $\mathrm{E}$ are measured as a function of penetration (h). The measurement for each sample was taken from 9 different zones (Figure 11a) to determine the average value, it was made to detect some mechanical properties' changes. The $\mathrm{H}$ and $\mathrm{E}$ values previously measured for the alone substrate and the values for undoped $\mathrm{SnO}_{2}$ sample were used as a reference to determine the influence of $\mathrm{Zn}$ quantity content in the MPs of $\mathrm{Zn}$ doped $\mathrm{SnO}_{2}$ films.

Figure $11 \mathrm{c}$ shows the characteristic load-penetration curves for each study samples. In this figure, we can see the variation of depth penetration. The mechanical behavior is elastic-plastic for all samples due to the shape of graphics [35]. The hardness and elastic modulus as a function of the (a)

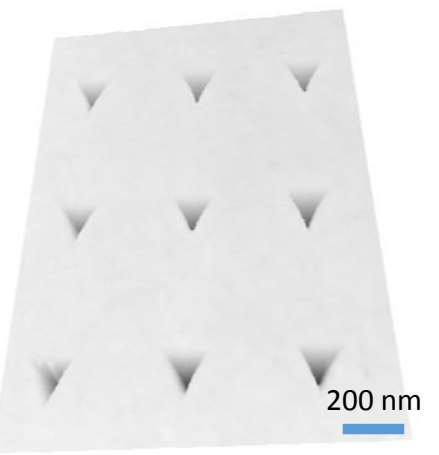

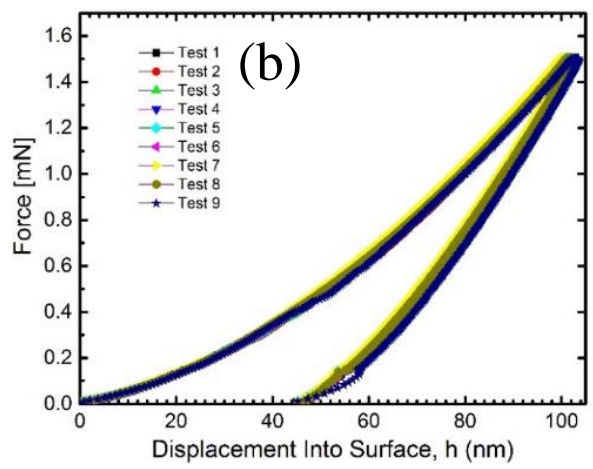

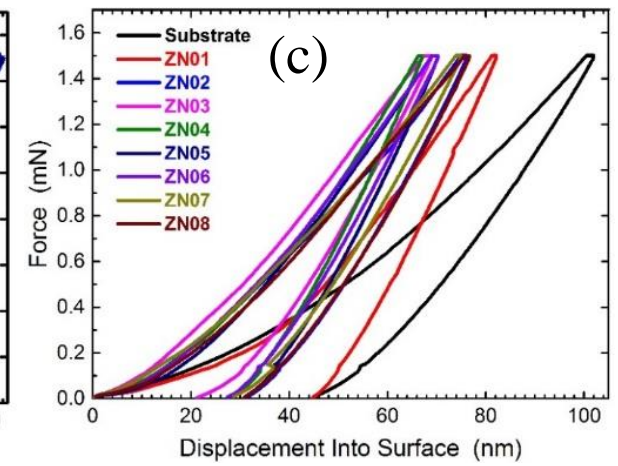

Figure 11. AFM image of (a) residual matrix indent and (b) characteristics depth vs force curves from nanoindentation tests for substrate (Corning 7059). Variation of depth vs force curves for (c) all samples. 
Table 2. Roughness and mechanical properties $\mathrm{H}$ and $\mathrm{E}$ according to the texture direction.

\begin{tabular}{|c|c|c|c|c|c|c|}
\hline Sample & $\begin{array}{c}{[\mathbf{Z n}] /[\mathbf{S n}]} \\
\text { in Solution } \\
\text { (at.\%) }\end{array}$ & $\begin{array}{l}\text { RMS } \\
\text { roughness } \\
(\mathrm{nm})\end{array}$ & $\begin{array}{c}\text { Hardness } \\
(\mathrm{H}) \\
(\mathrm{GPa})\end{array}$ & $\begin{array}{c}\text { Elastic } \\
\text { Modulus (E) } \\
(\mathrm{GPa})\end{array}$ & $\begin{array}{r}\text { Tex } \\
\text { We } \\
(\mathrm{w} \\
(200)\end{array}$ & $\begin{array}{l}\text { ture } \\
\text { ight } \\
\text { t\%) } \\
(101)\end{array}$ \\
\hline Substrate & & & $11 \pm 1$ & $92 \pm 1$ & & \\
\hline ZN01 & 0.0 & $17 \pm 1.7$ & $12 \pm 1$ & $138 \pm 10$ & & \\
\hline ZN02 & 1.0 & $21 \pm 0.5$ & $22 \pm 1$ & $168 \pm 5$ & 93 & 7 \\
\hline ZN03 & 2.9 & $18 \pm 1.7$ & $21 \pm 1$ & $195 \pm 4$ & 55 & 45 \\
\hline ZN04 & 4.8 & $15 \pm 1.8$ & $23 \pm 1$ & $195 \pm 7$ & 51 & 49 \\
\hline ZN05 & 6.5 & $11 \pm 0.2$ & $23 \pm 2$ & $176 \pm 6$ & 59 & 41 \\
\hline ZN06 & 9.1 & & $20 \pm 1$ & $158 \pm 5$ & 44 & 56 \\
\hline ZN07 & 23.8 & $9 \pm 1.1$ & $19 \pm 2$ & $140 \pm 6$ & 3 & 97 \\
\hline ZN08 & 33.3 & $8 \pm 0.3$ & $20 \pm 3$ & $147 \pm 4$ & 8 & 92 \\
\hline
\end{tabular}

penetration depth is presented in figure $12 \mathrm{a}$ and $12 \mathrm{~b}$, respectively. Figure 12a shows the hardness behavior for three representative samples as a function of penetration depth (substrate, ZN01 and ZN03). In these figures, we can distinguish three interval: region I which correspond to the thin film hardness only ( $0-125 \mathrm{~nm}$ penetration depth), in this region there is no influence from substrate; being this methodology well-established criterion in the literature [36]. Thus, the hardness of the samples ZN01 and ZN03 correspond to 12 and $21 \mathrm{GPa}$, respectively. In the case of substrate (reference) it remains constant at $\mathrm{H}=11 \mathrm{GPa}$. In the region II the hardness of the thin film is influenced by the substrate, it is due to both values start decrease. Finally, in Region III the hardness is completely influenced by the substrate, that is to say depth penetration reached to the substrate.

On the elastic modulus, Figure $12 \mathrm{~b}$ shows its behavior as a function of penetration depth for both samples and substrate, it has analogous behavior to the hardness. These elastic modulus for films ZN01 and ZN03 correspond to 137 and $195 \mathrm{GPa}$, respectively. Table 2 shows the $\mathrm{H}$ and $\mathrm{E}$ values behavior as a function of $\mathrm{Zn}$ dopant content. In general, the presence of $\mathrm{Zn}$ atoms in $\mathrm{SnO}_{2}$ thin film enhanced their MPs, these values are higher than undoped sample. The highest hardness and elastic modulus are obtained when the dopant level is around 4.8 at $\%$ of $\mathrm{Zn} / \mathrm{Sn}$, with hardness $23 \pm 1 \mathrm{GPa}$ (see Table 2), this value is $95 \%$ higher than undoped sample; related to the elastic modulus it reaches $195 \pm 7 \mathrm{GPa}$, it being $42 \%$ higher than undoped sample. However, for $\mathrm{Zn}$ dopant quantity with higher content than 4.8 at $\%$, it is detrimental to the mechanical property; but the values are still higher than pure $\mathrm{SnO}_{2}$ sample. Using similar methodology, the MPs values for $\mathrm{F}$ doped $\mathrm{SnO}_{2}$ films obtained by chemical vapor deposition show 5.1 and $71.1 \mathrm{GPa}$ for hardness and elastic modulus, respectively [37]. In our case, $\mathrm{H}$ and $\mathrm{E}$ values for $\mathrm{Zn}$ doped sample are higher than $\mathrm{F}$ doped $\mathrm{SnO}_{2}$. According to these values, our measurements are in the range.

The main influence in the MPs is due to the textured direction of the grown thin film, as a consequence of $\mathrm{Zn}$ dopant quantity content in the $\mathrm{SnO}_{2}$. Figure $12 \mathrm{c}$ shows the behavior of elastic modules and (200) texture direction (IPF values) as a function of $\mathrm{Zn}$ dopant content in $\mathrm{SnO}_{2}$ thin film; these IPF values show high correlation with the elastic modulus measurements, it means the $\mathrm{E}$ value is related with the crystal orientation. Figure $12 \mathrm{~d}$ shows the hardness values versus the amount of the $\mathrm{Zn}$ dopant in the $\mathrm{SnO}_{2}$ thin films; it can be noticed that for all dopant contents, samples show higher $\mathrm{H}$ value than undoped sample. From these performance, it can be noticed clearly that around $5 \%$ at. $\mathrm{Zn} / \mathrm{Sn}$ content sample present highest $\mathrm{H}$ and $\mathrm{E}$ values. This behavior is due to the textured direction of the thin film; it means the orientation of the unit cell on the substrate film is important to improve mechanical properties of $\mathrm{SnO}_{2}$ as thin (a)

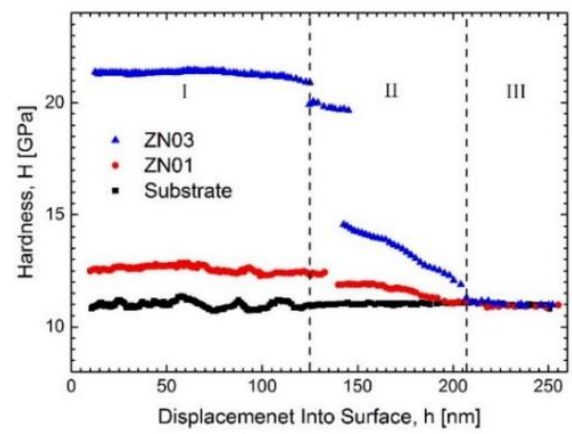

(b)

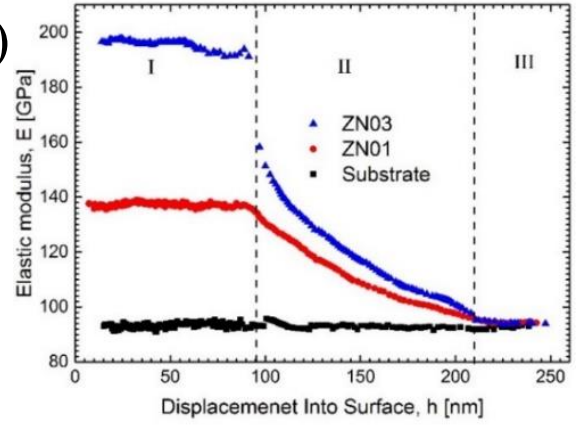

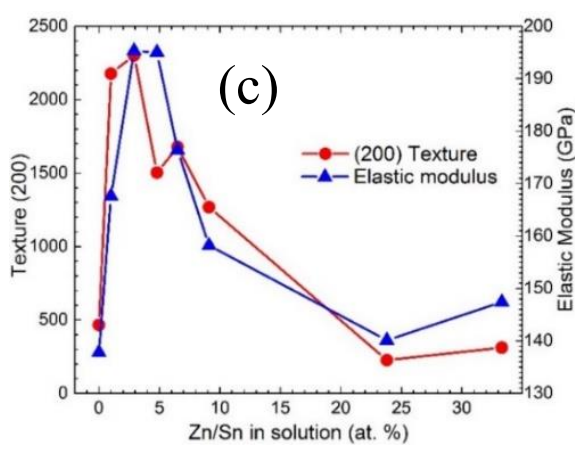

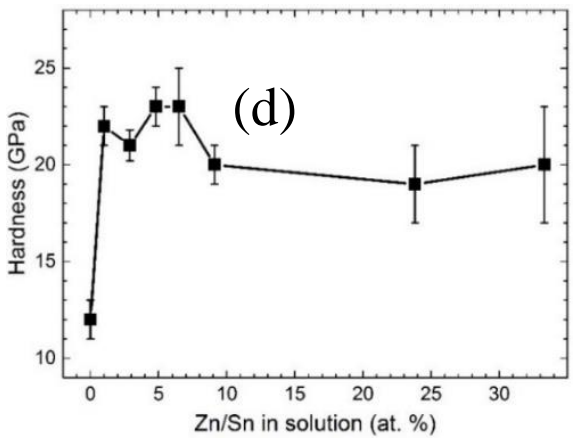

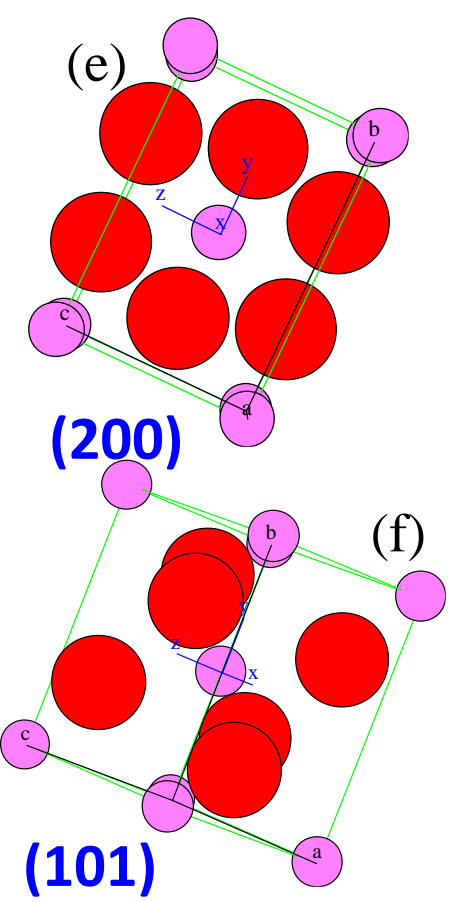

Figure 12. Behavior of the (a) hardness and (b) elastic modulus as a function of penetration depth, (c) E and (200) texture correlation, (d) Hardness as a function of the $\mathrm{Zn}$ content. $\mathrm{SnO}_{2}$ unit cell texture orientation along the (e) (200) and (f) (101) direction. 
film. Figures. 12e and $12 \mathrm{f}$ show the atoms arrangement according to the unit cell orientation along (200) and (101) texture direction, respectively. The atoms organization when the growth is along (200) direction are more compact than for (101) direction grown; it means, according to these atoms arrangement, the material change its MPs. Therefore, it could be concluded the ZN03 and ZN04 samples show better texturization (parallel to the substrate). Among the studies samples set in this report, they have better MPs due to the presence of both (200) and (101) crystal orientation direction with the same proportion (see Table 2 texture weight percentage column).

\section{Conclusions}

Textured films were synthesized by the spray pyrolysis technique, using an alcoholic solution of $\mathrm{SnCl}_{4} .5 \mathrm{H}_{2} \mathrm{O}$ and zinc acetate. It was demonstrated that this synthesis technique provides a powerful tool for creating a specific film structure orientation; it was shown that the influence of dopant concentration in start dilution affects the texture and shape of domain particles. A semi quantitative evaluation of inverse pole figure in the normal direction to the surfaces was obtained; d-spaces in the direction (200) and (101) have a marked tendency to grow parallel to the substrate; according to the $\mathrm{Zn}$ dopants content. The measured Young's module and Hardness values are higher than undoped materials; being this synthesis method adequate to change MPs of the $\mathrm{SnO}_{2}$ film. The measured Young's module show high correlation with the (200) growth texture direction. The MPs in this material is anisotropic, it changes according to the unit cell orientation on the substrate. These thin films with mechanical properties improved are ready to many technological applications.

\section{Acknowledgements}

The authors would like to thank to W. Antúnez, Luis de la Torre, C. Ornelas, E. Lestarjette and R. P. Talamantes for their technical aid at Laboratorio Nacional de NanoTecnología (NaNoTeCH) CIMAV, Chihuahua México. We appreciate to F. Paraguay-Ureta for her great help in correcting English. Thanks to CeMIE SOL-SENERCONACYT project $207450 /$ No P25 for the financial support.

\section{References}

[1]. W.Y. Jim, X. Liu, W.K. Yiu, Y.H. Leung, A.B. Djurišić, W.K. Chan, C.C. Liao, C. Surya, Phys. Status Solidi(b) 252, 553 (2015). [2]. K Chien, T.W. Coyle, J. of Thermal Spray Technol. 16, 886 (2007).

[3]. A. Kar, S. Sain, S. Kundu, A. Bhattacharyya, S. Kumar Pradhan, A. Patra, Chem. Phys. Chem. 16, 1017 (2015).

[4]. X. Huang, G. Zhao, M. Liu, F. Li, J. Qiao, S. Zhao, Electroch. Acta 83, $478(2012)$.

[5]. J.Y. Huang, L. Zhong, C.M. Wang, J.P. Sullivan, W. Xu, L.Q. Zhang, H. Fan, Science 330, 1515 (2010).
[6]. P. Li, Y. Lan, Q. Zhang, Z. Zhao, T. Pullerits, K. Zheng, Y. Zhou, J. of Physical Chemistry C 120, 9253 (2016).

[7]. A. Tirado-Guízar, G.E. Pina-Luis, F. Paraguay-Delgado, $M R S$ Communications 5, 63 (2015).

[8]. Y.L. Zhang, X.M. Tao, M.Q. Tan, J. Magn. Magn. Mater. 325, 7 (2013).

[9]. P. Raghani and B. Ramanujam, J. Appl. Phys. 115, 17C114 (2014).

[10]. N.A. Franco, K.M. Reddy, J. Eixenberger, D.A. Tenne, C.B. Hanna, A. Punnoose, J. Appl. Phys. 117, 17E515 (2015).

[11]. X. Li, Q. Yu, C. Yu, Y. Huang, R. Li, J. Wang, F. Guo, Y. Zhang, S. Gao, L. Zhao, J. Mater. Chem. A 3, 8076 (2015).

[12]. Z.G. Song, F. Ji, J. Ma, T. Ning, X. Pei, Y. Tan, Adv. Mater. Res. 771, 79 (2009).

[13]. B. Bhushan, Handb. of micro/nanotribology, 2nd Ed. (CRC Press, Boca Raton, FL, 1999).

[14]. G.M. Pharr, Mater. Sci. Eng. A 253, 151 (1998).

[15]. D. Tabor, Philos. Mag. A 74, 1207 (1996).

[16]. B. Bhushan, A.V. Kulkarni, W. Bonin, J.T. Wyrobek, Philos. Mag. A 74, 1117 (1996).

[17]. Q. Jiang, L. Zhang, H. Wang, X. Yang, J. Meng, H. Liu, J. You, Nature Energy 1, 16177 (2016).

[18]. X. Li, B. Bhushan, Scripta Materialia 47, 473 (2002).

[19]. Q.P. Tran, J.S. Fang, T.S. Chin, Mater. Sci. in Semiconductor Processing 40,664 (2015).

[20]. F. Abrinaei, M. T. Hosseinnejad, M. Shirazi, F. Shahgoli, $\underline{J}$. of Chemical Res. 40, 436 (2016).

[21]. J. Jiang, Y. Lu, B Kramm, F. Michel, C.T. Reindl, M.E. Kracht, M. Eickhoff, Physica Status Solidi(b) 253, 1087 (2016).

[22]. M. Miki-Yoshida, F. Paraguay-Delgado, W. Estrada-López, E. Andrade, Thin Solid Films 376, 99 (2000).

[23]. M. Vasanthi, K. Ravichandran, N.J. Begum, G. Muruganantham, S. Snega, A. Panneerselvam, P. Kavitha, Superlattices and Microstructures 55, 180 (2013).

[24]. F. Paraguay D, W. Estrada L., D.R. Acosta N., E. Andrade, M. Miki-Yoshida, Thin Solid Films 350, 192 (1999).

[25]. F. Paraguay D, M. Miki-Yoshida, J. Morales, J. Solis, W. Estrada L, Thin Solid Films 373, 137 (2000).

[26]. G.M. Pharr, Mater. Sci. Eng. A 253: 151 (1998).

[27]. R.A. Young, The Rietveld Method, 1st Ed. (Oxford University Press, New York, 1993).

[28]. L. Fuentes, Introducción al método Rietveld (Sociedad Mexicana de Cristalografía, México, 2004).

[29]. V. Bilgin, S. Kose, F. Atay, I. Akyuz, Mater. Lett. 58, 3686 (2004).

[30]. R. Sánchez Zeferino, U. Pal, R. Meléndrez, H.A. DuránMuñoz, M. Barboza Flores, J. Appl. Phys. 113, 064306 (2013).

[31]. F.C. Vásquez, F. Paraguay-Delgado, J.E. Morales-Mendoza, W. Antúnez-Flores, D. Lardizabal, G Alonso-Nuñez, G. Berhault, Superlattices Microstruct. 90, 274 (2016).

[32]. I.N. Sneddon, Int. J. Eng. Sci. Technol. 3, 47 (1965).

[33]. M.F. Doerner, D.S. Gardner and W.D. Nix, J. of Mater. Res. 1,845 (1986).

[34]. J.B. Pethica and W.C. Oliver, Physical Scr. 19, 61 (1987).

[35]. A. Alao, L. Yin, J. of Mater. Sci. \& Technol. 32, (5) 402 (2016).

[36]. C. Domínguez-Ríos, A. Hurtado-Macias, R. Torres-Sánchez, M. A. Ramo, J. González-Hernández, Eng. Chem. Res. 51(22), $7762(2012)$.

[37]. T.H. Fang, W.J. Chang, Appl. Surf. Sci. 252, 1863 (2005).

(C) 2018 by the authors; licensee SMCTSM, Mexico. This article is an open access article distributed under the terms and conditions of the Creative Commons Attribution license (http://creativecommons.org/licenses/by/4.0/). 